\title{
Customer Data Management Information System And Web-Based Digital Product Sales In CV. IT Brain Indonesia
}

\section{Sistem Informasi Pengelolaan Data Pelanggan Dan Penjualan Produk Digital Berbasis Web Pada CV. IT Brain Indonesia}

\author{
Muhammad Syafri Romadhon, Yulian Findawati \\ \{syafriroma19@umsida.ac.id, yulianfindawati@umsida.ac.id \}
}

Program Studi Informatika, Fakultas Sains dan Teknologi, Universitas Muhammadiyah Sidoarjo

\begin{abstract}
Customer Data Management Information System is a program or information system that functions to assist customer and sales data recording activities as well as product activation processes on CV. IT Brain Indonesia. This system is designed to record and input customer data from requests for demo software and customer consultations that come in daily via email marketing and also through whatsapp marketing before making a purchase and activation process. This system is shown for the marketing team on CV. IT Brain Indonesia is still using Microsoft Excel to record these data, which takes a long time to group customer needs on different sheets. In this case the author designed an Information System for Customer Data Management and Web-Based Digital Product Sales at CV. IT Brain Indonesia. The method used is the equivalence method and blackbox testing. The results of this study are in the form of a web-based information system intended for marketing and customer support that can group customer data according to their needs and record sales and product activation processes. This web-based information system was created using the CodeIgniter framework.
\end{abstract}

Keywords - Information system; customers; activation software system; sales system

\begin{abstract}
Abstrak. Sistem Informasi Pengelolaan Data Pelanggan adalah program atau sistem informasi yang befungsi untuk membantu kegiatan pencatatan data pelanggan dan penjualan serta proses aktivasi produk pada CV. IT Brain Indonesia. Sistem ini dirancang untuk mencatat dan menginputkan data pelanggan dari permintaan untuk software demo dan konsultasi pelanggan yang setiap hari masuk melalui email marketing dan juga melalui whastapp marketing sebelum melakukan pembelian dan proses aktivasi. Sistem ini ditunjukan untuk team marketing pada CV. IT Brain Indonesia yang masih menggunakan bantuan microsoft excel untuk mencatat data-data tersebut yang memakan waktu cukup lama untuk mengelompokan kebutuhan pelanggan pada sheet yang berbeda. Dalam hal ini penulis merancang Sistem Informasi Pengelolaan Data Pelanggan dan Penjualan Produk Digital Berbasis Web Pada CV. IT Brain Indonesia.Metode yang digunakan adalah metode equivalence dan pengujian blackbox. Hasil penelitian ini adalah berupa sistem informasi berbasis web yang ditunjukan untuk marketing dan customer support yang dapat mengelompokan data pelanggan sesuai kebutuhanya dan mencatat penjualan serta proses aktivasi produk. Sistem informasi berbasis web ini dibuat menggunakan framework CodeIgniter.
\end{abstract}

Kata Kunci - Sistem Informasi; Pelanggan; Sistem aktivasi software; Sistem penjualan

\section{Pendahuluan}

Sistem informasi pelanggan merupakan sistem yang memabntu untuk mempermudah kegiatan pengelolaan data pelanggan untuk mendapatkan informasi tentang pelanggan. Sistem informasi pelanggan dan penjualan produk digital ini digunakan untuk membantu mendata dan mengelompokan pelanggan yang belum ingin bertransaksi dan yang sudah bertransaksi agar memudahkan marketing untuk menfollow up dan mengambil keputusan untuk membuat pelanggan itu mau membeli produk digital atau sebutan lainya adalah closing.

IT Brain Indonesia adalah prusahan yang bergerak dibidang IT atau perangkat lunak dengan menjual berbagai produk digital atau software versi desktop seperti software toko, apotek, koperasi, akuntansi, klinik, dll. Teknik pemasaran yang digunakan adalah marketing online atau digital marketing dengan membuat artikel artikel seputar tips mengelola usaha mereka dengan bantuan software serta menyebar kontak marketing dengan membuat video dan diunggah ke social media atau forum-forum online. Walaupun bergerak adlam bidang IT pengelolaan data pelanggan bagian marketing masih manual hanya bantuan dari Microsoft excel.

Ketika customer menghubungi bagian marketing disitu team marketing langsung memberikan pertanyaan seputar kebuthuhan dari customer dan menjelaskan serta menawarkan software apa yang cocok dengan kebutuhanya. Terkadang tidak semua customer langsung tertarik untuk membeli setelah kita jelaskan dan kita beri versi demo dari software kami. Rata-rata customer yang menghubungi kami sudah menggunakan software dari perusahaan atau instansi lain namun kurang cocok karna penggunaanya yang sulit atau mahalnya biaya yang harus dikeluarkan. Data dari customer yang seperti ini kita kelompokan bedasarkan kebutuhan softwarenya serta alasan mereka masih belum membeli. Data tersebut berguna untuk marketing karna bisa untuk strategi untuk customer lain kedepanya. 
Permasalahan yang dihadapi tidak hanya disitu saja. Dalam sistem penjualan IT Brain Indonesia dilakukan dengan mengirim email ke pembeli.dan data pembelian tersebut juga masih tercatat manual hanya dengan bantuan Microsoft ecel. Masalah lainya ada di dalam aktivasi produk, customer yang baru membeli dan ingin menginstall software ketika sudah selesai proses instalasi biasanya akan muncul form aktivasi. Proses permintaan aktivasi ini biasanya dilakukan dengan mingirim foto form aktivasi ke whatsapp kami. Namun lagi-lagi proses aktivasi ini tidak tercatat sehinggan kerap para customer meminta aktivasi lebih dari satu kali.

Dari penelitian yang dilakukan oleh Muhammad Edwin Dirandinata (2017) yang menggunakan data pelanggan sebagai pendukung dari aktivitas marketing, kemudian dikembangkan dan menambahkan beberapa menu atau fitur baru kedalam penelitian yaitu untuk pencatatan aktivasi produk guna menghindari kecurangan dan pencatatan penjualan sebagai pendukung untuk pengambilan keputusan oleh marketing yang berguna untuk kerpeluan promosi.

Maka dari itu, penulis membuat penelitian tentang "Sistem Informasi Pengelolaan Data pelanggan Dan Penjualan Produk Digital Berbasis Web Pada CV. IT Brain Indonesia” yang bisa membantu menyelesaikan permasalahan dalam pencatatan data pelanggan dan penjualan serta membantu dalam mengurai kecurangan dalam permintaan aktivais produk. Sistem informasi ini berguna agar data-data dari penjualan serta pelanggan tertata rapid dan terorganisir guna memudahkan pererjaan marketing dalam pengambilan keputusan untuk promosi dan closing.

Sistem infromasi

Sistem informasi adalah susuan yang beraturan dari sebuah kegiatan yang saling bersangkutan dan merupakan susunan dari prosedur yang berhubungan, menjadi sinergi dari semua unsur yang ada didalamnya demi membantu kegiatan dan pekerjaan [7].

\section{Framework}

Framework adalah sebuah library untuk keperluan programmer dalam merancang dan membuat sistam informasi yang tersusun rapi menjadi sebuah rancangan yang berfungsi untuk memberikan kecepatan, kemudahan, serta konsisten dalam mengembangkan aplikasi [6].

\section{$M v c$}

Model View Controller atau MVC adalah sebuah pola atau teknik pemrograman yang memisahkan logika bisnis, data, dan presentasi [6]. Atau dalam Bahasa sederhananya memisahkan desain, data dan proses. Komponen dalam MVC ada tiga yaitu : Model yang menghubungkan data dari database ke webservice. View berupa halam dari web, yang terkhir Controller yang berfungsi sebagai penghubung antara data dan view.

\section{Boostrap}

Boostrap merupakan framework yang digunakan untuk mendesain halaman website secara responsive [4]. Responsive merupakan tampilan web yang akan mengikuti ukuran later device yang digunakan oleh user biasanya berupa desktop, mobile, tablet.

\section{Database}

Database adalah kumpulan dari informasi yang tersimpan dikomputer secara terancang yang dapat diperiksa menggunakan aplikasi komputer untuk memperoleh informasi [10]. Agar dapat mengelola database diperlukan perangkat lunak yang dikenal dengan sebutan DBMS. DBMS merupakan sistem yang memungkinkan user untuk membuat, mengelola, dan mengontrol serta mengkases database.

\section{Codeigniter}

CodeIgniter atau kita biasa mengenalnya dalam sebutan CI adalah sebuah framework yang digunakan untuk membangun aplikasi [6]. Tujuan utama dari CodeIgniter adalah untuk membantu developer dalam membuat aplikasi menjadi lebih cepat. Selain itu codeigniter juga mempunyai beberapa component seperti : Pattern MVC, Url Friendly, dll.

\section{METODE}

Penelitian ini dilakukan dan dilaksanakan di CV. IT Brain Indonesia, Sidoarjo. Penelitian ini dilakukan dalam rangka pembangunan sistem informasi pengelolaan data pelanggan dan pencatatan penjualan produk serta pencatatan data aktivasi pada perusahaan tersebut. Penelitian diawali dengan mengidentifikasi proses penjualan dari awal waktu customer pertamakali menghubungi bagian marketing serta pencatatan data-data kebutuhanya. Adapun hasil dari interview team marketing dan analisa proses yang ada didalamnya.

Metode yang digunakan adalah sebagai berikut: 
a. Observasi

b. Menyiapkan alat dan bahan

c. Wawancara dengan team marketing

d. Studi pustaka bedasarkan proses yang ada didalam CV. IT Brain Indonesia, dilakukan perancangan sistem informasi dengan cara: identifikasi kebutuhan, perancangan sistem informasi, implementasi, serta testing dan maintance

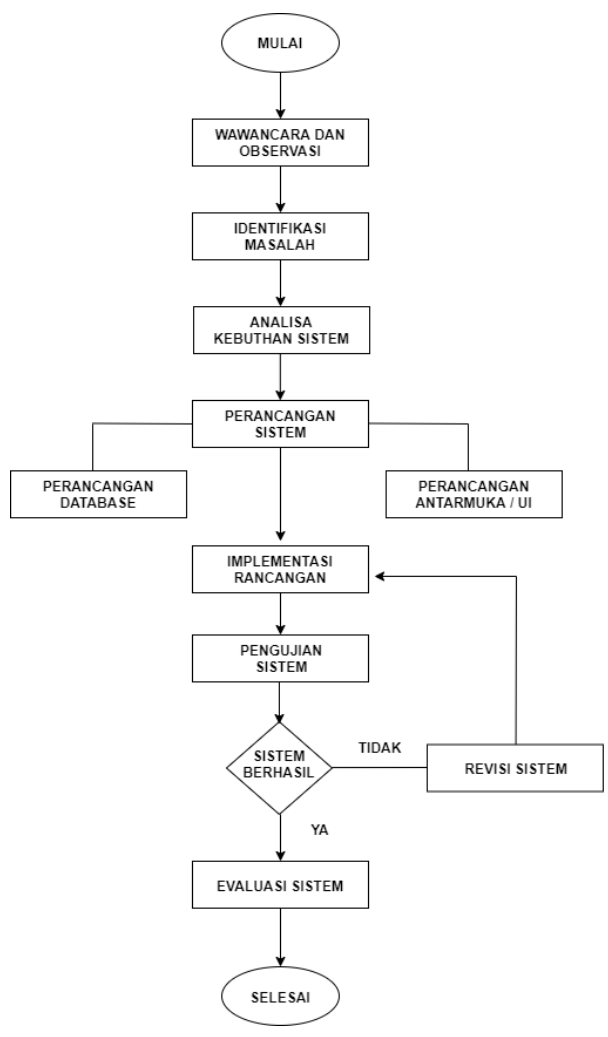

Gambar 2.1 Alur Penelitian

\section{Hasil dan Pembahasan}

Pada hasil dan pembahasan berikut saya bahasa tentang perancangan sistem dan pengujian sistem. Untuk perancangan sistem terdapat lima point yang saya bahas antaralain alur perancangan, DFD, relasi, desain rancangan, serta tampilan UI dari dashboard. Untuk pengujian disini saya menggunakan pengujian dari motode equivalence atau bisa disebut pengujian blackbox dimana pengujian dilakukan dengan memecah atau membagi input program.

\section{A. Identifikasi masalah dan analisa kebutuhan}

Masalah yang ditemukan pada saat melakukan observasi dan wawancara pada team marketing pada CV. IT Brain Indonesia adalah tidak adanya sistem untuk membantu marketing dalam mendata dan mengelompokan data customer sesuai kebutuhanya serta pencatatan penjualan software yang masih manual menggunakan excel. Dan satu lagi adanya masalah dalam pencatatan proses aktivasi produk yang kerap customer meminta lebih dari jumlah pembelian. Dari masalah diatas ditemukan beberapa kebutuhan untuk membantu kinejra team marketing adalah sebagai berikut :

- Pencatatan data pelanggan dengan bisa mengelompokan sesuai kebutuhan software

- Pembeda status pelanggan yang sudah melakukan pembelian dan yang belum

- Pencatatan Penjualan Software

- Pencatatan Proses Aktivasi dengan kondisi status pelanggan yang sudah membeli

- Laporan pelanggan. Penjualan, serta aktivasi.

Dari masalah kebutuhan diatas mendapatkan hasil dengan membuat rancangan dan mengimplementasikan ke dalam sistem informasi berbasis web yang dibuat untuk team marketing untuk mengatasi masalah yang dihadapi.

Adapun fitur dan kegunaan dari sistem informasi berbasis web yang dibuat antara lain : 
Procedia of Engineering and Life Science Vol. 1. No. 2 Juni 2021

Seminar Nasional \& Call Paper Fakultas Sains dan Teknologi (SENASAINS $3^{\text {rd }}$ )

Universitas Muhammadiyah Sidoarjo

- Menu Pelanggan berfungsi mendata data pelanggan sesuai kebutuhan dan status pelanggan.

- Menu Kategori berfungsi untuk menyimpan data kategori produk

- Menu Produk berfungsi untuk menyimpan data produk digital yang dijual

- Menu Penjualan berfungsi untuk melakukan proses transaksi penjualan dan mencatat transaksi penjualan.

- Menu Aktivasi digunakan untuk mencatat proses aktivasi produk dengan syarat pelanggan pelanggan yang sudah transaksi dan status pelanggan menjadi "sudah beli"

\section{B. Perancangan Sistem.}

Dfd level 0

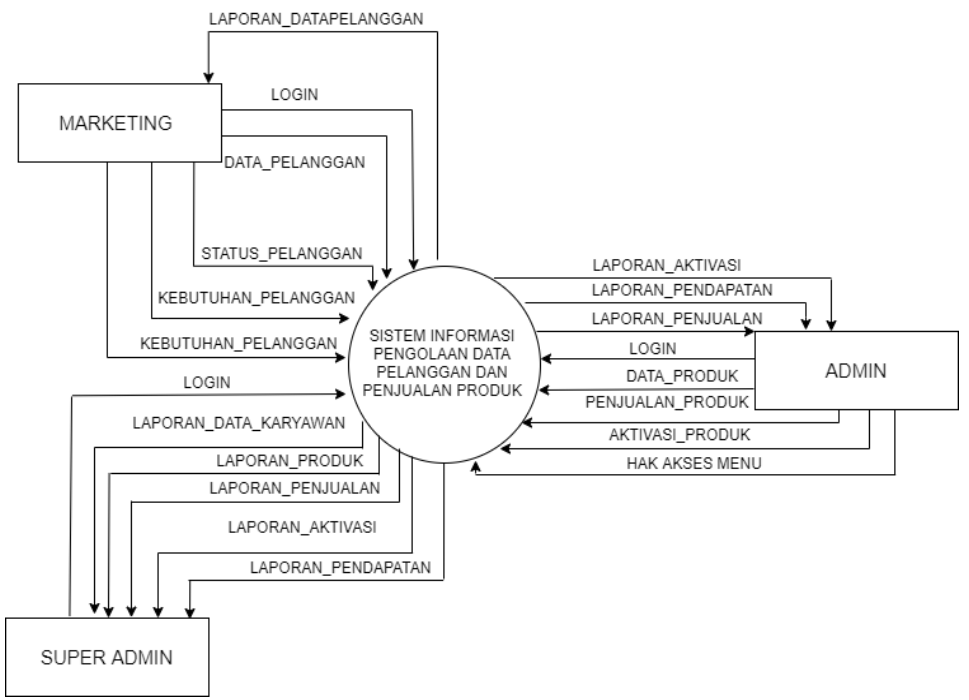

Gambar 1. DFD Level 0

Dfd level 1

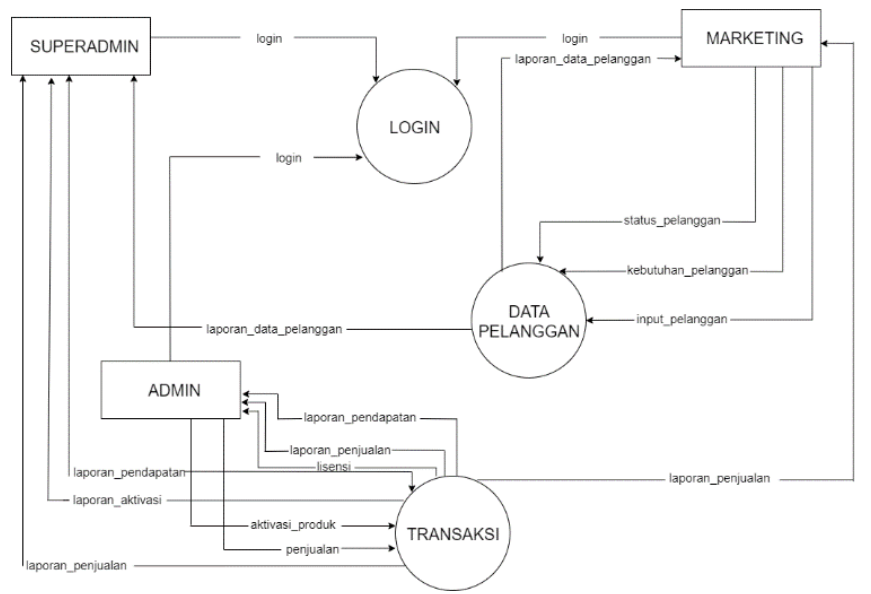

Gambar 2. DFD Level 1 
Procedia of Engineering and Life Science Vol. 1. No. 2 Juni 2021

Seminar Nasional \& Call Paper Fakultas Sains dan Teknologi (SENASAINS 3rd)

Universitas Muhammadiyah Sidoarjo

Desain tampilan perancangan

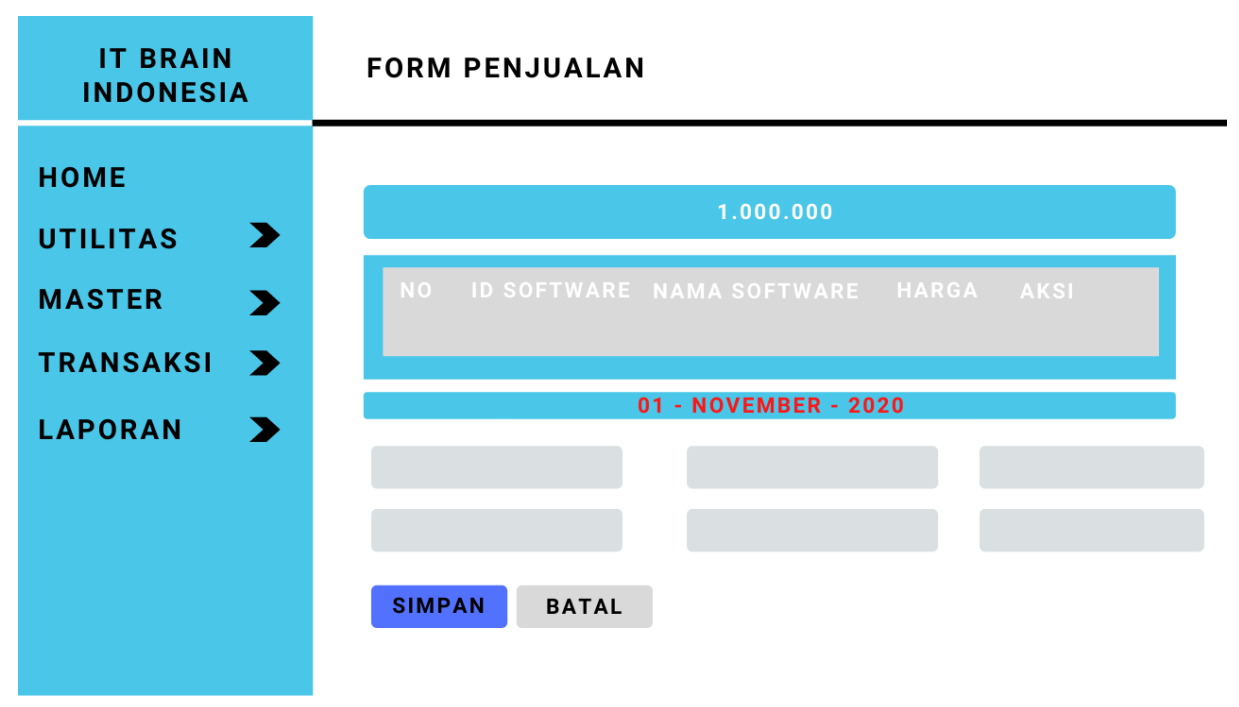

Gambar 3. Tampilan Rancangan Menu Pencatatan Penjualan

User interface

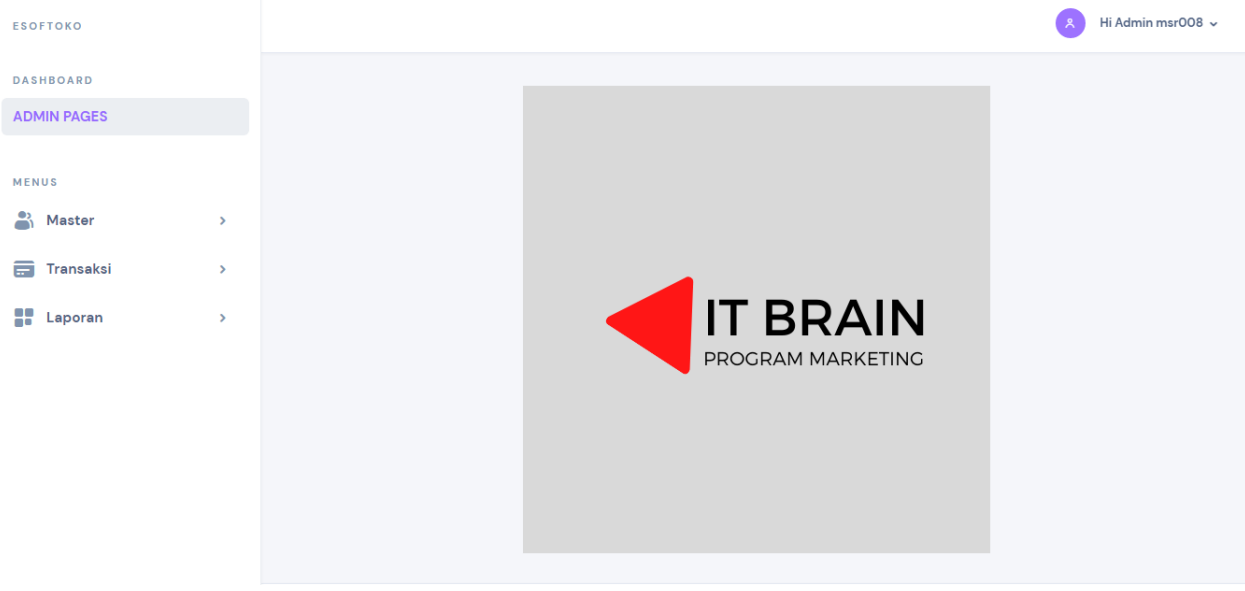

Gambar 4. Halaman Menu Penjualan

\section{Pengujian sistem}

Pengujian sistem dilakukan dengan bantuan para pengguna akhir. Pengujian ini berfokus pada fungsi-fungsi yang terlibat di sistem sehingga dapat menghasilkan output seperti yang diinginkan. Pengujian dilakukan terhadap tiga orang pengguna akhir yaitu: satu orang sebagai support customer, dua orang sebagai marketing.

Pengujian disini pegujian blackbox dimana pengujian dilakukan dengan memecah atau membagi domain input dari program. Kasus uji coba ini untuk menemukan kesalahan kesahalan pada pemrosesan atau dari seluruh data karakter. 
Procedia of Engineering and Life Science Vol. 1. No. 2 Juni 2021

Seminar Nasional \& Call Paper Fakultas Sains dan Teknologi (SENASAINS 3 ${ }^{\text {rd) }}$

Universitas Muhammadiyah Sidoarjo

Tabel 1. Pengujian Blackbox

\begin{tabular}{|c|c|c|c|c|c|}
\hline No & Pengujian & Test Case & $\begin{array}{c}\text { Hasil Yang } \\
\text { Diharapkan }\end{array}$ & $\begin{array}{c}\text { Hasil } \\
\text { Pengujian }\end{array}$ & Status \\
\hline 1 & $\begin{array}{l}\text { Pengujian Pada Menu } \\
\text { Karyawan }\end{array}$ & $\begin{array}{l}\text { Membuka menu } \\
\text { dan mencoba input, } \\
\text { update, delete }\end{array}$ & $\begin{array}{l}\text { Berhasil menabah, } \\
\text { mengubah, dan } \\
\text { menghapus data }\end{array}$ & $\begin{array}{l}\text { Sesuai } \\
\text { Harapan }\end{array}$ & Valid \\
\hline 2 & $\begin{array}{l}\text { Pengujian Pada Menu } \\
\text { Pelanggan }\end{array}$ & $\begin{array}{l}\text { Membuka menu } \\
\text { dan mencoba input, } \\
\text { update, delete }\end{array}$ & $\begin{array}{l}\text { Berhasil menabah, } \\
\text { mengubah, dan } \\
\text { menghapus data }\end{array}$ & $\begin{array}{l}\text { Sesuai } \\
\text { Harapan }\end{array}$ & Valid \\
\hline 3 & $\begin{array}{l}\text { Pengujian Pada Menu } \\
\text { Kategori }\end{array}$ & $\begin{array}{l}\text { Membuka menu } \\
\text { dan mencoba input, } \\
\text { update, delete }\end{array}$ & $\begin{array}{l}\text { Berhasil menabah, } \\
\text { mengubah, dan } \\
\text { menghapus data }\end{array}$ & $\begin{array}{l}\text { Sesuai } \\
\text { Harapan }\end{array}$ & Valid \\
\hline 4 & $\begin{array}{l}\text { Pengujian Pada Menu } \\
\text { Produk }\end{array}$ & $\begin{array}{l}\text { Membuka menu } \\
\text { dan mencoba input, } \\
\text { update, delete }\end{array}$ & $\begin{array}{l}\text { Berhasil menabah, } \\
\text { mengubah, dan } \\
\text { menghapus data }\end{array}$ & $\begin{array}{l}\text { Sesuai } \\
\text { Harapan }\end{array}$ & Valid \\
\hline 5 & $\begin{array}{l}\text { Pengujian Pada Menu } \\
\text { Penjualan }\end{array}$ & $\begin{array}{l}\text { Mencoba input } \\
\text { penjualan }\end{array}$ & $\begin{array}{l}\text { Berhasil melakukan } \\
\text { input penjualan }\end{array}$ & $\begin{array}{l}\text { Sesuai } \\
\text { Harapan }\end{array}$ & Valid \\
\hline 6 & $\begin{array}{l}\text { Pengujian Pada Menu } \\
\text { Aktivasi Produk }\end{array}$ & $\begin{array}{l}\text { Mencoba Input } \\
\text { Aktivasi }\end{array}$ & $\begin{array}{l}\text { Berhasil melakukan } \\
\text { input aktivasi }\end{array}$ & $\begin{array}{l}\text { Sesuai } \\
\text { Harapan }\end{array}$ & Valid \\
\hline 7 & $\begin{array}{l}\text { Pengujian Pada Menu } \\
\text { Laporan Pelanggan }\end{array}$ & $\begin{array}{l}\text { Membuka menu } \\
\text { dan mencetak } \\
\text { Laporan }\end{array}$ & $\begin{array}{l}\text { Berhasil mencetak } \\
\text { laporan pdf }\end{array}$ & $\begin{array}{l}\text { Sesuai } \\
\text { Harapan }\end{array}$ & Valid \\
\hline 8 & $\begin{array}{l}\text { Pengujian Pada Menu } \\
\text { Laporan Penjualan }\end{array}$ & $\begin{array}{l}\text { Membuka menu } \\
\text { dan mencetak } \\
\text { Laporan }\end{array}$ & $\begin{array}{l}\text { Berhasil mencetak } \\
\text { laporan pdf }\end{array}$ & $\begin{array}{l}\text { Sesuai } \\
\text { Harapan }\end{array}$ & Valid \\
\hline 9 & $\begin{array}{l}\text { Pengujian Pada Menu } \\
\text { Laporan Aktivasi }\end{array}$ & $\begin{array}{l}\text { Membuka menu } \\
\text { dan mencetak } \\
\text { Laporan }\end{array}$ & $\begin{array}{l}\text { Berhasil mencetak } \\
\text { laporan pdf }\end{array}$ & $\begin{array}{l}\text { Sesuai } \\
\text { Harapan }\end{array}$ & Valid \\
\hline
\end{tabular}

Dari pengujian fungsional menggunakan metode equivalence dapat disimpulkan bawaha pengelolaan atauran seperti menambah, mengubah, menghapus, dan menampilkan tidak menemukan kesalahan dan dapat berfungsi sesuai keinginan. Dari pengujian diatas maka dapat diketahui presentasi pencapaian sebagai berikut :

$$
\begin{gathered}
\text { Tercapai }=\frac{9}{9} \times 100 \%=100 \% \\
\text { Gagal }=\frac{0}{9} \times 100 \%=100 \%
\end{gathered}
$$

\section{Pengujian kepuasan pengguna}

Pengujian ini terdiri atas 2 bagian yaitu customer support dan team marketing. Adapun hasil pengujianya adalah sebagai berikut : 
Procedia of Engineering and Life Science Vol. 1. No. 2 Juni 2021

Seminar Nasional \& Call Paper Fakultas Sains dan Teknologi (SENASAINS 3 ${ }^{\text {rd }}$ )

Universitas Muhammadiyah Sidoarjo

Tabel 2. Pengujian oleh customer support dan marketing

\begin{tabular}{c|l|c|c}
\hline No & \multicolumn{1}{|c|}{ Pertanyaan } & Penilaian & Jumlah \\
\hline 1 & $\begin{array}{l}\text { Apa website sistem informasi data pelanggan } \\
\text { dan penjualan produk diperlukan untuk } \\
\text { mengelola dan mengelompokan data } \\
\text { pelanggan? }\end{array}$ & $\begin{array}{l}\text { Setuju } \\
\text { Apa website sistem informasi data pelanggan } \\
\text { dan penjualan produk membantu dalam } \\
\text { pencatatan penjualan produk dan proses } \\
\text { aktivasi? }\end{array}$ & Setuju \\
\hline 3 & $\begin{array}{l}\text { Apa website sistem informasi data pelanggan } \\
\text { dan penjualan produk dapat membantu } \\
\text { mempermudah mencetak laporan? }\end{array}$ & Setuju & 3 \\
\hline 4 & $\begin{array}{l}\text { Apakah penataan dan penyajian informasi } \\
\text { memudahkan untuk membaca dan mencari } \\
\text { informasi data pelanggan? }\end{array}$ & Setuju & 3 \\
\hline 5 & $\begin{array}{l}\text { Apakah sistem informasi data pelanggan dan } \\
\text { penjualan ini mempermudah pekerjaan? }\end{array}$ & Setuju & 3 \\
\hline 6 & $\begin{array}{l}\text { Apakash User Interface Sistem Informasi } \\
\text { data pelanggan dan penjualan produk ini } \\
\text { menarik dan mudah digunakan? }\end{array}$ & Setuju & 3 \\
\hline
\end{tabular}

Tabel 3. Bobot Jawaban

\begin{tabular}{l|c}
\hline \multicolumn{1}{c|}{ Jawaban } & Bobot \\
\hline Sangat Setuju & 4 \\
\hline Setuju & 3 \\
\hline Tidak Setuju & 2 \\
\hline Sangat Tidak Setuju & 1 \\
\hline
\end{tabular}

- Dari table diatas dilihat bahwa jumlah nilai dari ketiga responden untuk pertanyaan pertama adalah 3. Maka nilai rata-ratanya adalah $6 / 3=2$. Sedangkan presentasi nilainya adalah : $(3 / 4) \times 100 \%=75 \%$

- Dari table diatas dilihat bahwa jumlah nilai ketiga responden untuk pertanyaan kedua adalah 3. Maka nilai rata-ratanya adalah $6 / 3=2$. Sedangkan presentasi nilainya adalah : $(3 / 4) \times 100 \%=75 \%$

- Dari table diatas dilihat bahwa jumlah nilai dari ketiga responden untuk pertanyaan ketiga adalah 3. Maka nilai rata-ratanya adalah $6 / 3=2$. Sedangkan presentasi nilainya adalah : $(3 / 4) \times 100 \%=75 \%$

- Dari table diatas dilihat bahwa jumlah nilai ketiga responden untuk pertanyaan keempat adalah 3. Maka nilai rata-ratanya adalah $6 / 3=2$. Sedangkan presentasi nilainya adalah : $(3 / 4) \times 100 \%=75 \%$

- Dari table diatas dilihat bahwa jumlah nilai ketiga responden untuk pertanyaan kelima adalah 3. Maka nilai rata-ratanya adalah $6 / 3=2$. Sedangkan presentasi nilainya adalah : $(3 / 4) \times 100 \%=75 \%$

- Dari table diatas dilihat bahwa jumlah nilai ketiga responden untuk pertanyaan keenam adalah 3. Maka nilai rata-ratanya adalah $6 / 3=2$. Sedangkan presentasi nilainya adalah : $(3 / 4) \times 100 \%=75 \%$

Perhitungan keseluruhan merupakan hasil perhitungan rata-rata skor dari seluruh pertanyaan. Adapun hasil perhitungan keseluruh pertanyaan jika dijabarkan satu persatu adalah sebagai berikut :

$(75 \%+75 \%+75 \%+75 \%+75 \%+75 \%) / 6=75 \%$

\section{KESIMPULAN}

Dengan adanya sistem informasi ini dapat membantu team marketing pada CV. IT Brain Indonesia dalam mengelompokan data pelanggan dengan mudah sesuai kebutuhanya dan sesuai status pembelianya, Serta mempermudah mencatat penjualan produk dan mencatat proses aktivasi software guna menghindari kecurangan dalam permintaan aplikasi. Dan marketing tidak perlu memikirkan lagi dengan laporan penjualan, data pelanggan, serta laporan aktivasi produk yang keluar. 


\section{REFERENSI}

[1] Agus Heryanto., Dedi., Nur Anjani. (2015). Sistem Informasi Administrasi Pelanggan Berbasis Web (Studi Kasus PT. Profilia Indotech). ISBN 2088-1762.

[1] Khilyatin Ulin Fitri., Azizah Fatmawati. (2019). Sistem Informasi Pelanggan Pada Bengkel Marno Jaya Motor. ISSN 2541-4518.

[2] Zulkarnain. (2020). Sistem Informasi Pengelolaan Data Pelanggan Pada CV. Indoprint Banda Aceh. ISSN 2723 7079.

[3] Muhammad Edwin Diradinata. (2017). Rancang Bangun Aplikasi Pengelolaan Data Pelanggan Untuk Mendukung Aktivitas Pemasaran Pada PT. Lazizaa Rahmat Semesta.

[4] Rian Ariona S,ST. (2013). Tutorial Fundamental Dalam Mempelajari HTML \& CSS.

[5] Achmad Solichin S.Kom. (2010). Pemrograman Web Dengan PHP dan MySQL V1.0

[6] Ibnu Daqiqil Id, M.Ti. (2011). Perkenalan Framework Code Igniter : Sebuah Panduan dan Best Practice.

[7] Ahmad Lukman. (2018). Sistem Informasi Manajemen. ISBN 978-602-9451-03-0.

[8] Wulandari Siska Aprilia. (2015). Sistem Informasi Penjualan Produk Berbasis Web Pada Chanel Distro Pringsewu. Jurnal TAM (Technology Acceptance Model) Vol 4.

[9] Meiska Firstiara Maudi, Arief Laila Nugroho, Bandi Sasmito. (2014). Desain Aplikasi Sistem Informasi Pelanggan PDAM Berbasis WebGIS (Studi Kasus Kota Denmark). ISSN 2337-845X

[10] Rullyta Primasari. (2011). Perancangan Sistem Informasi Pengelolaan Data Pelanggan Pada Perusahaan Daerah Air Minum (PDAM) Kota Pekanbaru 